\title{
Investigation of silk fibroin nanoparticle-decorated poly(L-lactic acid) composite scaffolds for osteoblast growth and differentiation
}

This article was published in the following Dove Press journal:

International Journal of Nanomedicine

8 March 2017

Number of times this article has been viewed

\author{
Biao-Qi Chen' \\ Ranjith Kumar Kankala ${ }^{1,2}$ \\ Ai-Zheng Chen ${ }^{1,2}$ \\ Ding-Zhu Yang' \\ Xiao-Xia Cheng' \\ $\mathrm{Ni}-\mathrm{Na}$ Jiang ${ }^{1,2}$ \\ Kai Zhu ${ }^{3,4}$ \\ Shi-Bin Wang ${ }^{1,2}$ \\ 'Institute of Biomaterials and Tissue \\ Engineering, ${ }^{2}$ Fujian Provincial Key \\ Laboratory of Biochemical Technology, \\ Huaqiao University, Xiamen, Fujian, \\ ${ }^{3}$ Department of Cardiac Surgery, \\ Zhongshan Hospital, Fudan University, \\ ${ }^{4}$ Shanghai Institute of Cardiovascular \\ Disease, Shanghai, People's Republic \\ of China
}

Correspondence: Ai-Zheng Chen Institute of Biomaterials and Tissue Engineering, Huaqiao University, 668 Jimei Avenue, Xiamen, Fujian 361021, People's Republic of China

Tel/fax +865926162326

Email azchen@hqu.edu.cn

Shi-Bin Wang

Fujian Provincial Key Laboratory of Biochemical Technology, Huaqiao University, 668 Jimei Avenue, Xiamen, Fujian 36I02I, People's Republic of China

$\mathrm{Tel} / \mathrm{fax}+865926162208$

Email sbwang@hqu.edu.cn

\begin{abstract}
Attempts to reflect the physiology of organs is quite an intricacy during the tissue engineering process. An ideal scaffold and its surface topography can address and manipulate the cell behavior during the regeneration of targeted tissue, affecting the cell growth and differentiation significantly. Herein, silk fibroin (SF) nanoparticles were incorporated into poly(L-lactic acid) (PLLA) to prepare composite scaffolds via phase-inversion technique using supercritical carbon dioxide ( $\mathrm{SC}-\mathrm{CO}_{2}$ ). The SF nanoparticle core increased the surface roughness and hydrophilicity of the PLLA scaffolds, leading to a high affinity for albumin attachment. The in vitro cytotoxicity test of SF/PLLA scaffolds in L929 mouse fibroblast cells indicated good biocompatibility. Then, the in vitro interplay between mouse preosteoblast cell (MC3T3-E1) and various topological structures and biochemical cues were evaluated. The cell adhesion, proliferation, osteogenic differentiation and their relationship with the structures as well as SF content were explored. The SF/PLLA weight ratio (2:8) significantly affected the MC3T3-E1 cells by improving the expression of key players in the regulation of bone formation, ie, alkaline phosphatase (ALP), osteocalcin (OC) and collagen 1 (COL-1). These results suggest not only the importance of surface topography and biochemical cues but also the potential of applying SF/PLLA composite scaffolds as biomaterials in bone tissue engineering.
\end{abstract}

Keywords: super critical fluids, surface topography, bone engineering, cellular adhesion, alkaline phosphatase

\section{Introduction}

Many surgeries usually lead to injuries and tissue/organ defects, which, in turn, postsurgery result in a risk of disease transmission and high failure rates after treatment. ${ }^{1,2}$ The recovery, replacement or regeneration of the damaged area remains challenging to surgeons. Promisingly, tissue engineering provides an alternative to heal injuries and regeneration of tissue/organ. ${ }^{3-5}$ Compared to two-dimensional (2D) implants, three-dimensional (3D) biocompatible scaffolds have more spatial freedom of cellular growth and support the new tissue formation. ${ }^{6,7}$ However, the reflection of the physiology of organs during tissue engineering process is highly challenging due to tissue complexity. A biodegradable scaffold can serve as a framework as well as a temporary carrier before occupancy of new tissue and also modulate various important cell behaviors. ${ }^{8,9}$ Cells are inherently sensitive to their supporting substrate. ${ }^{10-12}$ Interconnected macroporous scaffold network facilitates cell infiltration, growth, nutrient diffusion and removal of metabolic waste during tissue development. ${ }^{13,14}$

Recently, construction of surface topography has attracted a great interest in the development of micrometric to nanometric range in different types of cells. ${ }^{6,15-19}$ 
Various kinds of topographies such as grooves, pillars and pits have been shown to affect cellular alignment, attachment, proliferation and differentiation. ${ }^{20-23}$ In a way, the N-cadherin expression and $\beta$-catenin signaling activation of MC3T3-E1 cells were affected by the titanium (Ti) surfaces with micro- and/or nanotopography and the $\mathrm{N}$-cadherin/ $\beta$-catenin interaction addressed the indirect mechanotransduction. ${ }^{24}$ The incorporation of hydroxyapatite (HA) into the poly(Llactic acid) (PLLA) scaffold enhanced the cell spreading and significantly improved the expression of vinculin in MC3T3-E1 cells. ${ }^{25}$ In addition, the surface roughness of a nanoconstruct has also been proved to enhance the cellmatrix interactions and subsequently influence the long-term function of the cells. ${ }^{26,27}$

Cell fate determination is also influenced not only by the surface topography but also by the biochemical cues. For instance, human mesenchymal stem cells (hMSCs) on a well-defined surface of microtextures and biochemical supplements (osteogenic medium) consistently expressed a high level of osteoblast-specific markers and had a greater amount of bone matrix. ${ }^{28}$ In addition, the collagen membranes containing growth differentiation factor 5 significantly enhanced alkaline phosphatase (ALP) levels and cell proliferation activities without any cytotoxicity in MC3T3-E1 cells. ${ }^{29}$ In tissue engineering, the surface topography and chemical cues of the scaffolds have shown to be effective regulators of cell-scaffold interactions and cell behaviors. ${ }^{30,31}$ The evaluation of these interactions is quite essential for tissue formation, and the rational design of a scaffold enables its development.

Indeed, fabrication of porous materials by supercritical carbon dioxide $\left(\mathrm{SC}-\mathrm{CO}_{2}\right)$ techniques has significant implications for tissue engineering. ${ }^{32}$ Recently, we have successfully constructed PLLA scaffolds with different surface topographies by phase-inversion technique, using $\mathrm{SC}-\mathrm{CO}_{2}$ as a nonsolvent. ${ }^{33,34}$ These scaffolds possessed varied as well as controllable size pores and resulted in excellent mechanical properties. Being encouraged by the results, we were motivated to prepare high-performance tissue engineering scaffolds utilizing silk fibroin (SF) nanoparticles by solutionenhanced dispersion using SC-CO $\mathrm{CO}_{2}$ (SEDS) process and subsequently encapsulated them into PLLA to prepare SF/PLLA composite scaffolds (Figure 1).

PLLA is a US Food and Drug Administration (FDA)approved synthetic aliphatic polyester and has been widely used in tissue engineering. ${ }^{35}$ The $3 \mathrm{D}$ porous structures of PLLA are essential commodities in the development of tissue engineering scaffolds. However, owing to its hydrophobic nature, these structures cannot support cell adhesion. Therefore, surface modification strategies have been employed to mimic the natural microenvironment to control cell growth. ${ }^{25,36,37}$

$\mathrm{SF}$ is one of the natural fibrous protein polymers possessing unique surface functional groups, as well as several attractive properties such as excellent cell compatibility, adaptable biodegradability, hydrophilicity and cell affinity. ${ }^{38}$

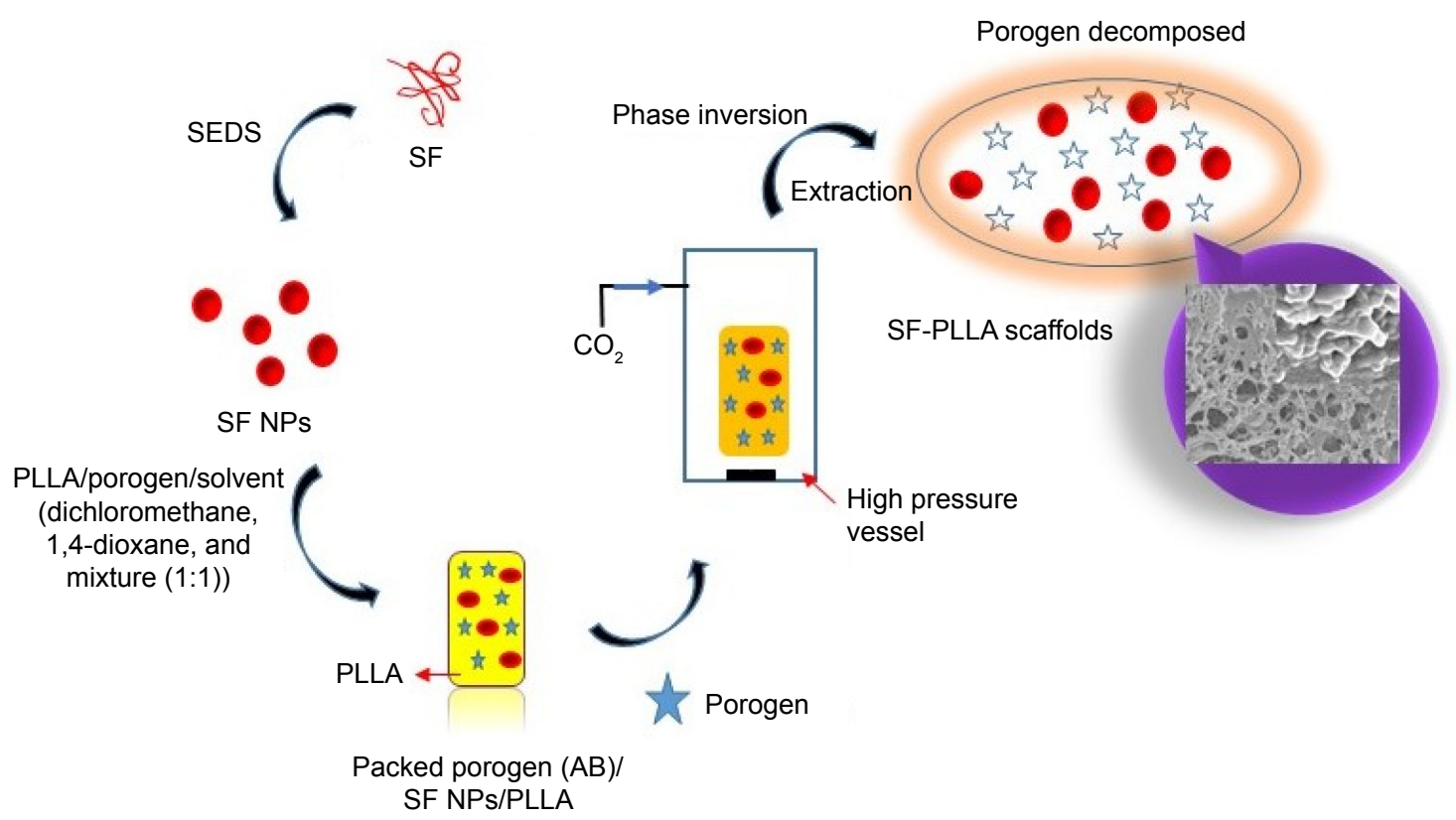

Figure I Schematic representation elucidating the sequential steps of the scaffold design.

Abbreviations: AB, ammonium bicarbonate; SEDS, solution-enhanced dispersion using supercritical carbon dioxide; SF, silk fibroin; PLLA, poly(L-lactic acid); NPs, nanoparticles. 
Moreover, it has been used as a suture material because of its excellent mechanical properties, and different SF-based material formats for tissue engineering and regenerative medicine have been developed. ${ }^{39}$ Although there have been a few studies about the use of SF nanoparticles for drug delivery, none of them have explored the potential of SF to be modified to improve the surface roughness and hydrophilicity of the PLLA scaffolds.

In this study, we evaluated the effect of various solvents namely dioxane, dichloromethane and their mixture used to prepare scaffolds. In addition, these SF nanoparticle-embedded scaffolds are intended to improve the surface roughness of the scaffolds and can serve as a better alternative in tissue engineering process. Subsequently, the effect of SF:PLLA ratio packing was also optimized. Furthermore, the effects of the PLLA and SF/PLLA composite scaffolds on adhesion, proliferation and osteogenic differentiation of MC3T3-E1 cells were evaluated. The osteoblast differentiation of the cells was analyzed by the osteoblast-specific markers (ALP, osteocalcin [OC] and collagen 1 [COL-1]) to reveal the underlying implications of SF/PLLA composite scaffolds for bone tissue engineering in vivo.

\section{Experimental section Materials}

PLLA with an inherent viscosity of $3.5 \mathrm{dL} / \mathrm{g}(0.1 \%[\mathrm{w} / \mathrm{v}]$ in chloroform, $25^{\circ} \mathrm{C}$ ) was purchased from the Daigang Biological Co., Ltd. (Jinan, China). SF powder was purchased from Xintiansi Biotech Co., Ltd. (Zhejiang, China). Dichloromethane (99.8\% purity), 1,4-dioxane (99.8\% purity) and ammonium bicarbonate (AB) were purchased from the Sinopharm Chemical Reagent Co., Ltd. (Shanghai, China); 1,1,1,3,3,3-hexafluoroisopropanol (HFIP, 99.5\% purity) was purchased from Aladdin reagent Co., Ltd (Shanghai, China) and $\mathrm{CO}_{2}$ of $99.9 \%$ purity was purchased from the Rihong Air Products Co., Ltd. (Xiamen, China). All other compounds were of analytical purity.

\section{Methods}

\section{Preparation of SF nanoparticles}

The SF nanoparticles were prepared by SEDS method as reported by Zhao et al. ${ }^{40}$ Briefly, $0.5 \%$ (w/v) SF solution in $\mathrm{HFIP}$ and $\mathrm{SC}-\mathrm{CO}_{2}$ were sprayed together through a specially designed coaxial nozzle to enhance the dispersion effect of the solution droplets. The SF solution $(0.5 \mathrm{~mL} / \mathrm{min})$ and $\mathrm{SC}-\mathrm{CO}_{2}$ $\left(1,500 \mathrm{~L} / \mathrm{h}, 10 \mathrm{MPa}, 35^{\circ} \mathrm{C}\right)$ were pumped through the inner and external routes of the nozzle, respectively. Later, fresh $\mathrm{SC}-\mathrm{CO}_{2}$ was used to scour the products for $\sim 30 \mathrm{~min}$ in order to remove the residual organic solvent. During the process of scouring, the operating conditions of the system were kept constant as described earlier. After washing, the high-pressure vessel was slowly depressurized and the product was collected.

\section{Preparation of PLLA and SF/PLLA scaffolds}

The PLLA scaffolds were prepared as reported by Deng et al. ${ }^{33}$ Briefly, the PLLA was dissolved in different solvents, namely dichloromethane, 1,4-dioxane and dichloromethane/1,4-dioxane (1:1, v:v), and stirred until homogenous. AB particles (AB/PLLA [w/w] ratio: 20:1) of selected size (size range: $300-600 \mu \mathrm{m}$ ) were added to the solution and mixed vigorously. The polymer/salt/solvent paste was cast as samples with a diameter of $15.0 \mathrm{~mm}$ and a height of $5.0 \mathrm{~mm}$ and then rapidly placed in the high-pressure vessel. Subsequently, the $\mathrm{SC}-\mathrm{CO}_{2}\left(15 \mathrm{MPa}, 35^{\circ} \mathrm{C}\right)$ was pumped into the vessel, the mixture was permitted to stand for $2 \mathrm{~h}$ for phase separation, and then a constant flow rate $(\sim 5 \mathrm{~g} / \mathrm{min})$ of fresh $\mathrm{SC}-\mathrm{CO}_{2}$ flushed the samples at a constant temperature and pressure for another $2 \mathrm{~h}$ to remove the organic solvent. The system was then slowly depressurized, and the samples were taken out of the vessel. Finally, the PLLA scaffolds were obtained by using vacuum drying until the AB particles were completely removed.

Eventually, the composite SF/PLLA scaffolds were prepared by suspending SF nanoparticles in organic solution by ultrasonic dispersion, and the PLLA solution was added to it. Then, the mixed solution was cast as samples, according to the same procedures described earlier (Figure 1). The resultant SF/PLLA composite scaffolds were further employed for the morphological characterization.

The surface morphology of the SF nanoparticles was examined by field emission scanning electron microscopy (FESEM, S-4800; Hitachi, Tokyo, Japan). The average particle size and polydispersity index (PDI) of the nanoparticles were analyzed by dynamic light scattering measurement using a Zetasizer Nano ZS (ZEN-3600; Malvern, UK).

\section{In vitro cytotoxicity assay}

The cytotoxicity tests of PLLA and SF/PLLA scaffolds were performed using alamarBlue ${ }^{\circledR}$ colorimetric assay (Invitrogen, Eugene, OR, USA) against mouse fibroblast cell line L929 cells (Shanghai Institute of Biochemistry and Cell Biology, China), cultured in Dulbecco's Modified Eagle's Medium (DMEM; Gibco, Grand Island, NY, USA), added with 10\% (v/v) fetal bovine serum (FBS; Gibco) and 1\% penicillin/ streptomycin (Gibco) at $37^{\circ} \mathrm{C}$ and $5 \% \mathrm{CO}_{2}$. Briefly, L929 cells were seeded into 96 -well plates at a density of 5,000 
cells per well. After $24 \mathrm{~h}$ of incubation, the medium was replaced by leach liquors of PLLA or SF/PLLA scaffolds at different concentrations $(0.5,1.0$ and $2.0 \mathrm{mg} / \mathrm{mL})$. The medium alone and phenol-dispersed medium were set as the negative and positive controls, respectively. Furthermore, the reagent solution $(10 \%, \mathrm{v} / \mathrm{v})$ was added to each well and allowed to stand for $4 \mathrm{~h}$. The fluorescence of alamarBlue was recorded eventually $\left(\lambda_{\mathrm{Ex} / \mathrm{Em}}=570 / 600 \mathrm{~nm}\right)$.

\section{Cell culture}

Mouse preosteoblast cell line MC3T3-E1 cells (Shanghai Institute of Biochemistry and Cell Biology, China) were cultured in Minimal Essential Medium-alpha ( $\alpha$-MEM; Gibco) containing 10\% (v/v) FBS and 1\% penicillin/ streptomycin, at $37^{\circ} \mathrm{C}$ in $5 \% \mathrm{CO}_{2}$ atmosphere. The culture medium was replaced every $2-3$ days. After $70 \%-80 \%$ of confluence, cells were trypsinized and then seeded onto the scaffolds for the cell-matrix interaction studies. Prior to cell seeding, scaffolds were sterilized using 75\% ethanol overnight and then rinsed with phosphate-buffered saline (PBS) three times to remove ethanol. The samples were placed in the 24-well culture plate and preincubated with the $\alpha$-MEM before the experiment.

\section{Cell adhesion and proliferation assay}

MC3T3-E1 cells were seeded at a density of 500,000 cells $/ \mathrm{mL} /$ well on PLLA and SF/PLLA composite scaffolds. After $4 \mathrm{~h}$ of seeding, the medium was removed, the scaffolds were washed with PBS twice, and then nonadherent cells were collected and counted using a hemocytometer. The cell adhesion rate was calculated by the following equation:

Cell adhesion rate $=1-($ nonadherent cells $/$ seeded cells $)$

To evaluate cell proliferation on different scaffolds, 100,000 cells/well were seeded on the scaffolds. The medium was removed and the scaffolds were washed with PBS at different culture time points of 3, 5 and 7 days. Cell proliferation was determined by alamarBlue test by adding $1 \mathrm{~mL}$ of alamarBlue work reagent to each well and incubated on an orbital shaker $\left(50 \mathrm{rpm}, 37^{\circ} \mathrm{C}, 5 \% \mathrm{CO}_{2}\right)$ for another $4 \mathrm{~h}$. Thereafter, $100 \mu \mathrm{L}$ of each sample was transferred to a 96-well culture plate and fluorescence was measured $\left(\lambda_{\text {Ex/Em }}=570 / 600 \mathrm{~nm}\right)$.

\section{Cell viability assay}

The viability of cells in different scaffolds was verified by assessing the live-dead cells at the end of culture. Specific stains were used to differentiate them, ie, calcein AM and propidium iodide (PI) for live and dead cells, respectively. PI is specific as it can enter only through the damaged membrane. Briefly, scaffolds were incubated in PBS containing calcein AM and PI (Sigma, St Louis, MO, USA) for $20 \mathrm{~min}$ at $37^{\circ} \mathrm{C}$ and then washed twice with PBS. Images showing stained cells were captured using a laser scanning confocal microscope (LSM710; Zeiss, Oberkochen, Germany).

\section{Osteogenic differentiation assay}

To induce in vitro osteogenic differentiation of MC3T3-E1 cells, the effect of initial cell seeding density and different concentrations of dexamethasone in the differentiation medium was investigated. A total of 1,000 and 10,000 cells were seeded in 24-well culture plate per well, cultured in an $\alpha$-MEM including $10 \%$ FBS and $1 \%$ penicillin/streptomycin for $48 \mathrm{~h}$. The medium was then changed to osteoblast differentiation medium containing various concentrations of dexamethasone. Staining of calcium deposits was performed using Alizarin Red, and evaluation of osteogenesis was done by visualizing the mineralization of the extracellular matrix (ECM).

The MC3T3-E1 cell suspensions (30,000 cells/mL) were seeded on PLLA and SF/PLLA scaffolds. After culturing for $48 \mathrm{~h}$, cells were treated with osteoblast differentiation medium containing dexamethasone, $\beta$-glycerol phosphate and ascorbic acid. Cell-specific metabolic activities were studied after 7, 14 and 21 days by measuring the ALP activity, OC and COL-1 expression levels. At the end of the prescribed time periods, the scaffolds were transferred to a new 24-well plate followed by PBS washes, ruptured by ultrasound, and the cell lysates were analyzed. The ALP activity was measured by an ALP activity assay kit (Jiancheng Ltd., Nanjing, China); OC and COL-1 were measured using enzyme-linked immunosorbent assay kit (ELISA; Jiancheng Ltd., Nanjing, China) following the manufacturer's instructions.

\section{Statistical analysis}

All data were presented as mean \pm standard deviation $(n=3)$. The statistical analysis of all the experimental data was performed using SPSS version 17.0. Analysis of variance (ANOVA) single factor analysis was conducted at a defined level of statistical significance as $P<0.05$.

\section{Results}

\section{Structural morphology of PLLA and SF/PLLA scaffolds}

Herewith, the PLLA scaffolds were prepared using the reported procedure, which contains both micro- and 

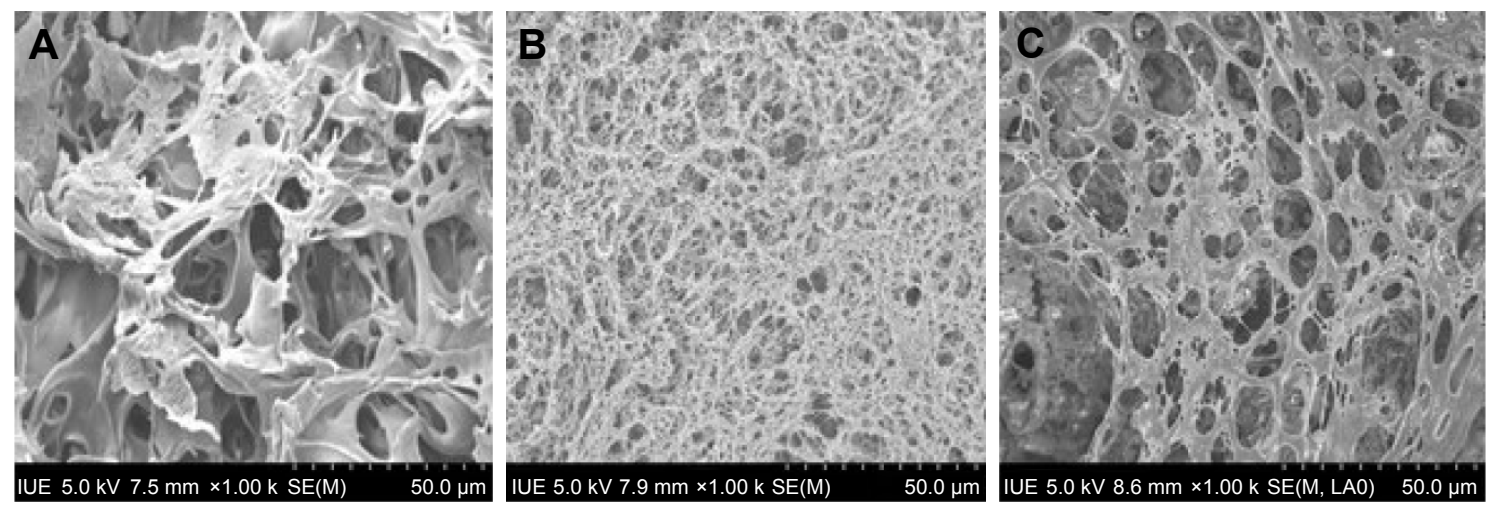

Figure 2 SEM images of the PLLA scaffolds (scale bar, $50 \mu \mathrm{m}$ for all panels) prepared from different organic solutions: (A) dichloromethane, (B) I,4-dioxane and (C) dichloromethane/I,4-dioxane I:I (v:v).

Abbreviations: SEM, scanning electron microscope; PLLA, poly(L-lactic acid); IUE, Institute of Urban Environment.

macro-interconnected pores directed by the porogen, ie, $\mathrm{AB}$, as shown in Figure 2. The PLLA scaffolds precipitated after various solvent treatments resulted in different structural properties including pore texture and its size. The scaffolds in dichloromethane solution resulted in a cellular structure with a pore size ranging from 2 to $40 \mu \mathrm{m}$, and the pore wall was thick and dense (Figure 2A), while the scaffolds precipitated from the 1,4-dioxane solution represented a nanofibrous network possessing $\sim 8 \mu \mathrm{m}$ of pore size (Figure 2B). In addition, the dichloromethane/1,4-dioxane mixture (1:1 [v:v]) solution was also used, and the scaffolds showed a homogeneous microcell structure consisting of nanoscale pores, with the rough inner pore wall (Figure 2C). These results demonstrated that scaffolds with different morphologies could be precipitated using different solvents but the scaffolds obtained by solvent mixture resulted in fine particle texture, which is more suitable for cell growth.

From the SEM images, as shown in Figure S1, it is evident that the surface morphology of SF nanoparticles exhibits a smooth surface and a spherical shape. The average particle size and the PDI (Mw/Mn) were about 296.5 $\pm 1.2 \mathrm{~nm}$ and 0.151 , respectively. SF nanoparticles in the mixture of dichloromethane and 1,4-dioxane dispersed well in the PLLA solution, resulting in composite scaffolds (Figure 3). The microstructure of the composite scaffolds resulted in a change in surface texture after addition of SF nanoparticles. This also shows that SF nanoparticles were located on the pore wall and improved the surface roughness of the scaffolds.

\section{In vitro cytotoxicity study}

The toxicity of the PLLA and SF/PLLA scaffolds was tested by the alamarBlue assay. L929 cells were cultured at different concentrations of the leach liquors of scaffolds in the medium for 24 and $48 \mathrm{~h}$. It was observed that most of the cells $(>90 \%)$ at each concentration grew well, and the relative growth rate (relative to the negative control) was over $90 \%$ (Figure $4 \mathrm{~A}$ ). After $48 \mathrm{~h}$, the relative growth rate (Figure 4C) has shown the high cell viability ( $>80 \%$ ) of all the PLLA scaffolds. As shown in Figure 4B and D, the cytotoxicity of the SF/PLLA composite scaffolds was inappreciable with a cell relative growth rate of $>80 \%$, indicating no significant cytotoxicity of SF/PLLA composite scaffolds. The bright field images of cells (Figure S2) also indicated a consistent phenomenon that the L929 cells grew normally, well spread and remained in a fusiform morphology within $48 \mathrm{~h}$. Thus, the PLLA and SF/PLLA scaffolds resulted in excellent biocompatibility.

\section{Cell adhesion}

The cell adhesion rate of MC3T3-E1 on PLLA and SF/PLLA scaffolds with different topographical morphologies was also analyzed (Figure 5). After incubating PLLA scaffolds for $4 \mathrm{~h}$, the MC3T3-E1 cell adhesion rate of mixture group (dichloromethane/1,4-dioxane) reached 75\%, which was significantly higher than that of the dichloromethane and 1,4dioxane group (Figure 5A). These data can be correlated with the scaffold structure that can improve the albumin attachment leading to a higher cell adhesion. ${ }^{41}$ The cell adhesion rate of the SF/PLLA composite scaffolds (Figure 5B) was higher than the PLLA scaffolds at which SF/PLLA with the optimum weight ratio of 2:8 resulted in the highest cell adhesion rate (89\%). The addition of SF nanoparticles altered the surface properties and roughness of PLLA scaffolds and, therefore, improved the protein adsorption and cell adhesion.

\section{Cell proliferation}

The ability of PLLA and SF/PLLA scaffolds to stimulate proliferation of MC3T3-E1 cells was evaluated by harvesting and compared at different time points (1, 3 and 7 days). 

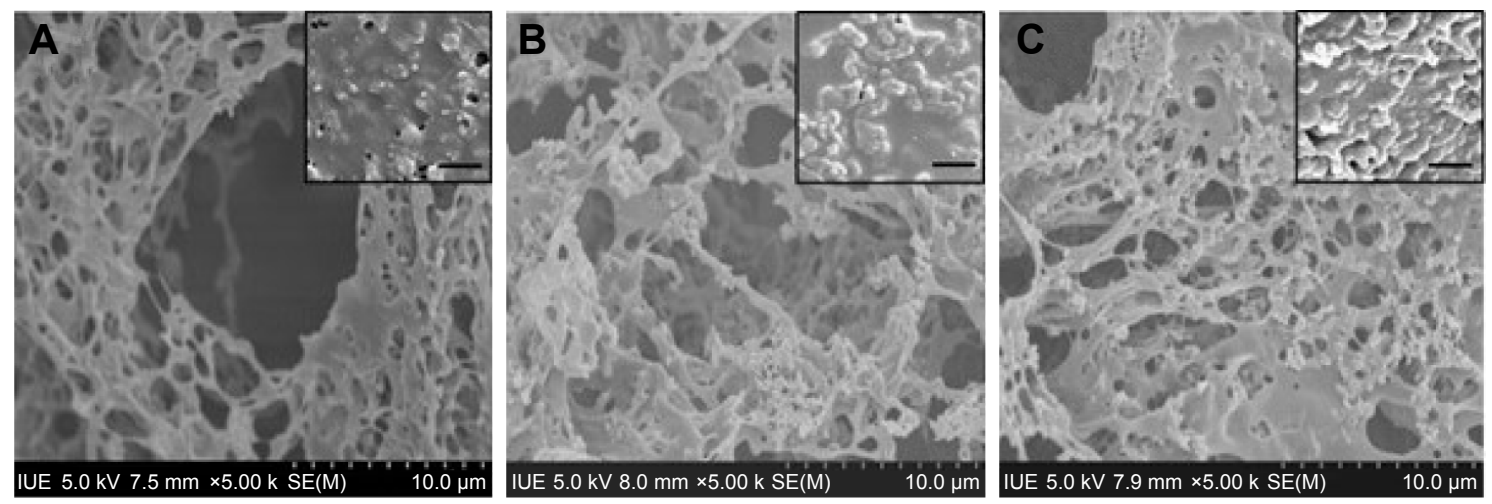

Figure 3 SEM images of SF/PLLA composite scaffolds (scale bar, $10 \mu \mathrm{m}$ for all panels) with the inset images displaying the magnified view (scale bar, $2 \mu \mathrm{m}$ ) prepared by dichloromethane/I,4-dioxane (I:I, v:v): (A) SF/PLLA (I:9, w/w), (B) SF/PLLA (2:8, w/w) and (C) SF/PLLA (3:7, w/w).

Abbreviations: SEM, scanning electron microscope; SF, silk fibroin; PLLA, poly(L-lactic acid); IUE, Institute of Urban Environment.

A

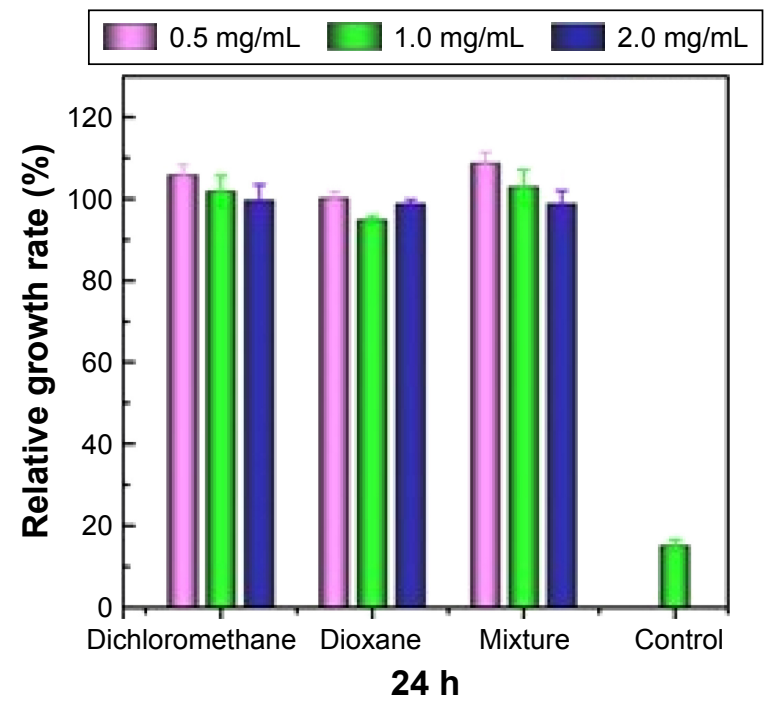

C

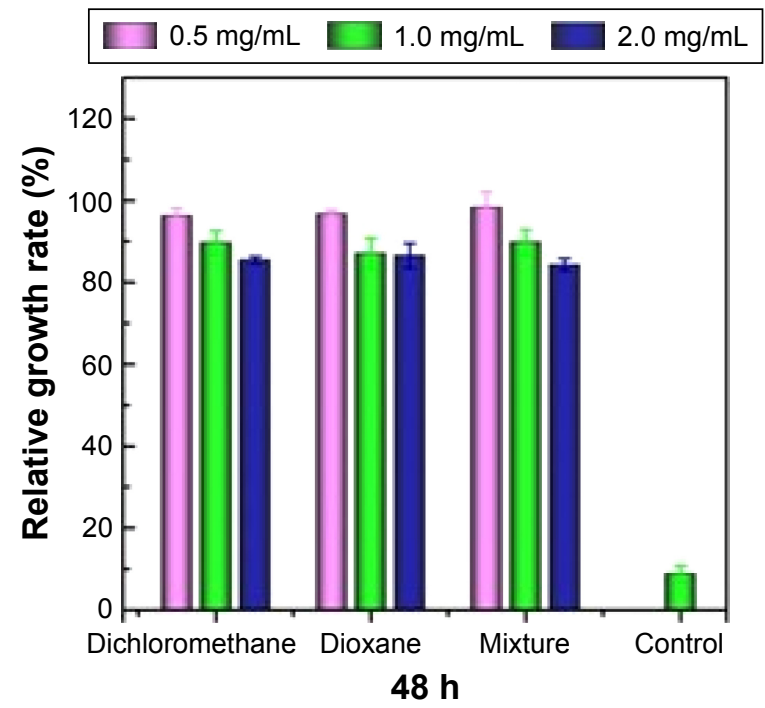

B
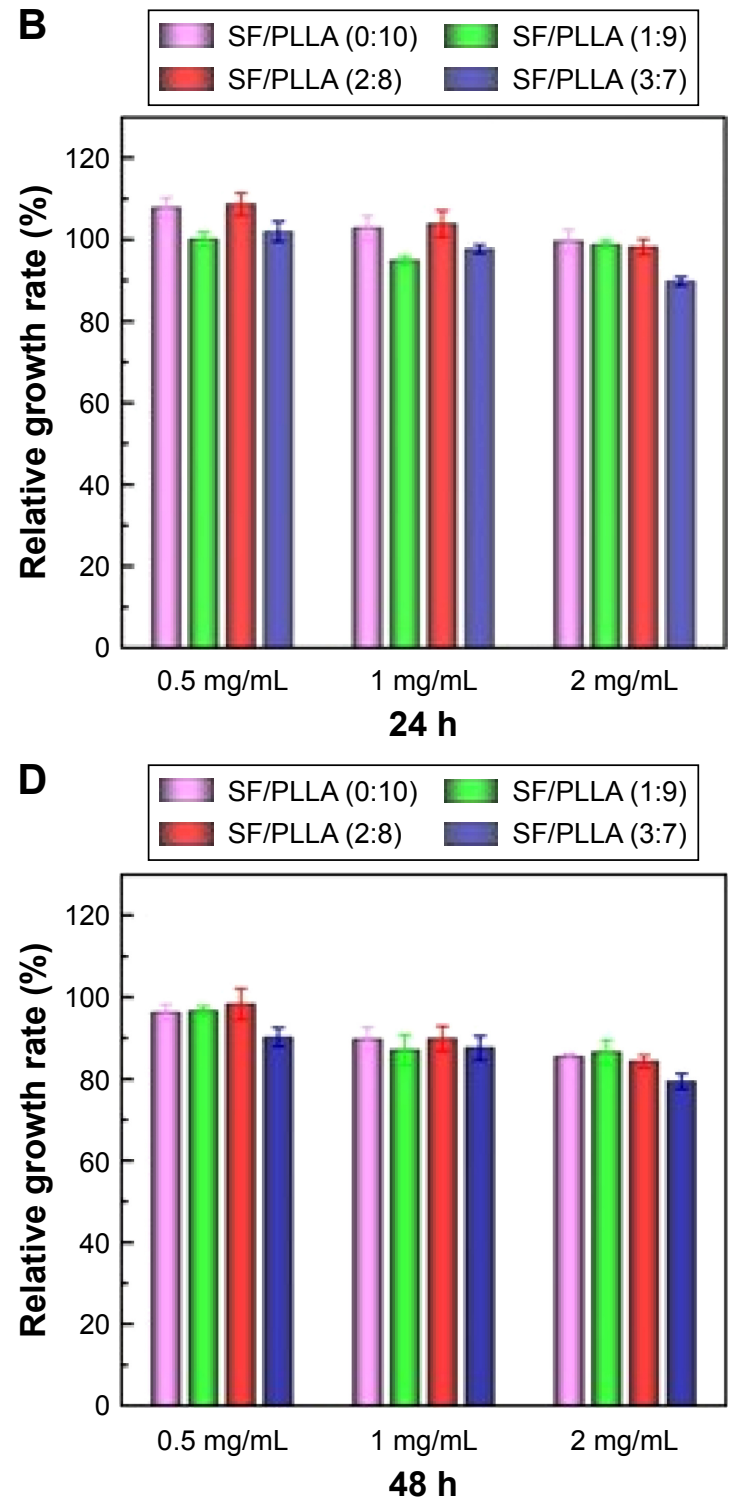

Figure 4 Relative growth rate of L929 cells after incubation with PLLA scaffolds prepared with different types of solvents and SF/PLLA composite scaffolds containing different ratios of SF content for various incubation periods, (A and B) 24 and (C and D) $48 \mathrm{~h}$.

Abbreviations: PLLA, poly(L-lactic acid); SF, silk fibroin; h, hours. 

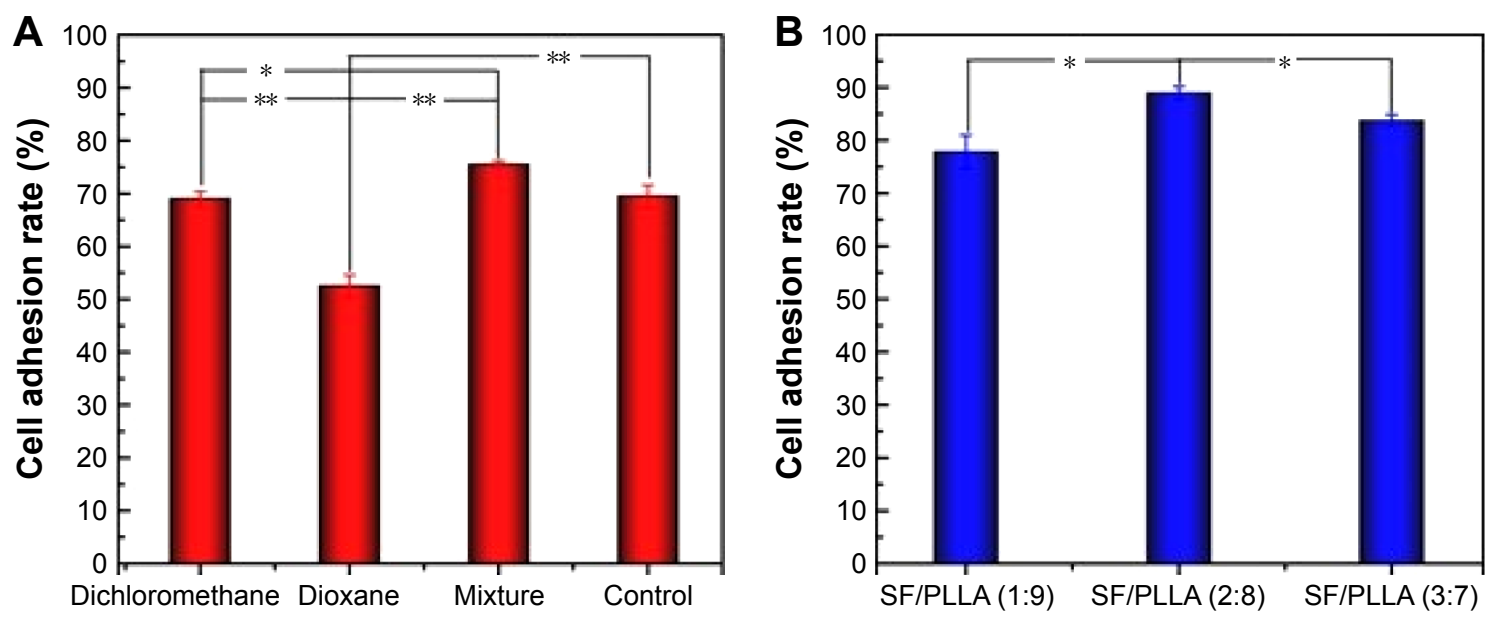

Figure 5 Cell adhesion rate analysis of MC3T3-EI cells on (A) PLLA scaffolds prepared using different types of solvents, (B) SF/PLLA composite scaffolds containing different ratios of $S F$ content $(* P<0.05, * * P<0.01)$

Abbreviations: PLLA, poly(L-lactic acid); SF, silk fibroin.

The results showed that the proliferation of MC3T3-E1 cells cultured on scaffolds of mixture group was obviously increased in comparison with other groups (Figure 6A). The cell proliferation data (Figure 6B) indicated an increase in metabolic activity on SF/PLLA (2:8) composite scaffolds. However, the proliferation was decreased in the SF/PLLA (3:7) treatment group, indicating the third day of the transition period. While the cells showed a continuous proliferation on mixture solution and SF/PLLA (2:8) groups throughout the entire period of culture. The influence of SF nanoparticles agglomerates could be the reason for this effect. The scaffolds have large active surface area in SF/PLLA (2:8), which promotes extensive cell-material interactions, whereas, the SF nanoparticles form agglomerates in the composite scaffolds at a higher concentration (SF/PLLA, 3:7), which ultimately hinders the interconnectivity between pores and limits the space for cell communication with surroundings. Furthermore, the cell proliferation of the SF/PLLA (1:9) treatment group resulted in no significant change indicating that the metabolic activity of cells in this group was stabilized and concentration of SF nanoparticles incorporated influenced the property of PLLA scaffolds. The LSCM micrographs of cell viability (Figure 7) further confirmed the abovementioned results.

\section{Cell viability}

Based on the abovementioned results, the optimized formulations, ie, scaffolds, prepared using dichloromethane as well
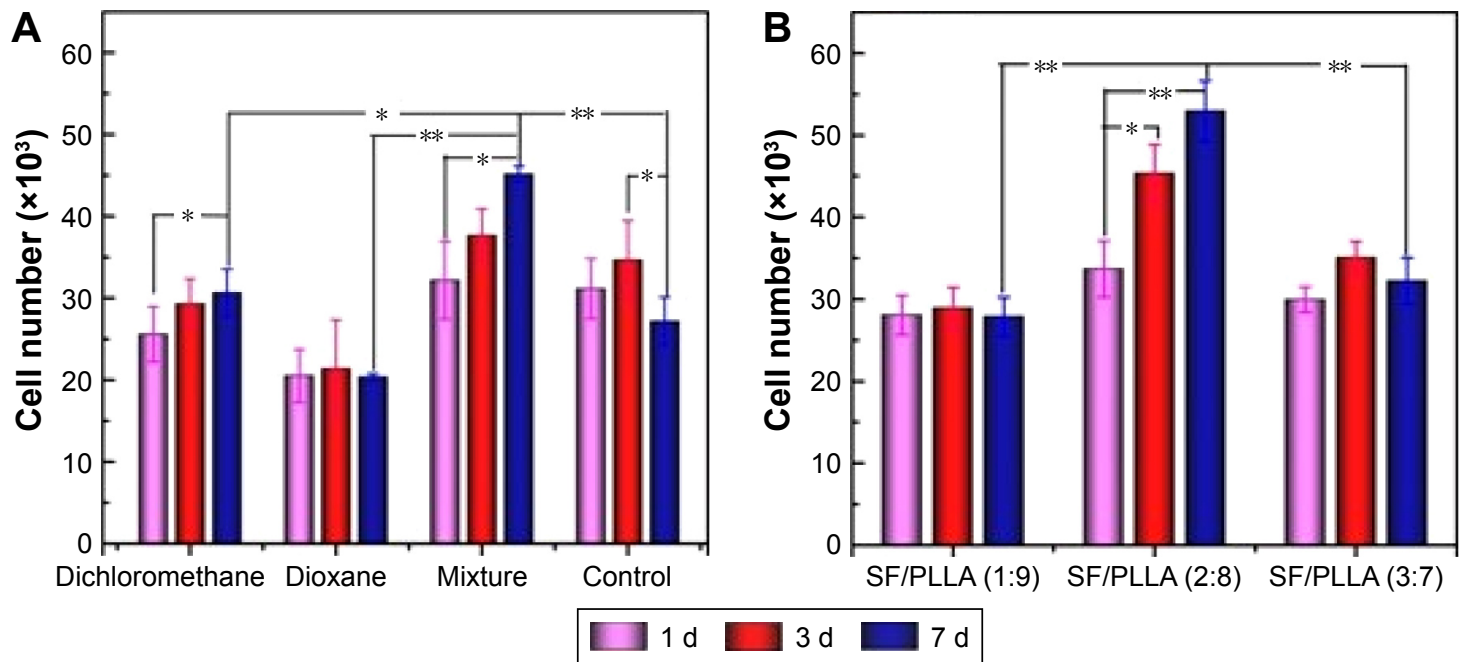

Figure 6 Cell proliferation rate analysis of MC3T3-EI cells, showing the cell number after treatment with (A) PLLA scaffolds prepared using different types of solvents, (B) SF/PLLA composite scaffolds containing different ratios of SF content $(* P<0.05, * * P<0.0$ l).

Abbreviations: PLLA, poly(L-lactic acid); SF, silk fibroin; d, days. 

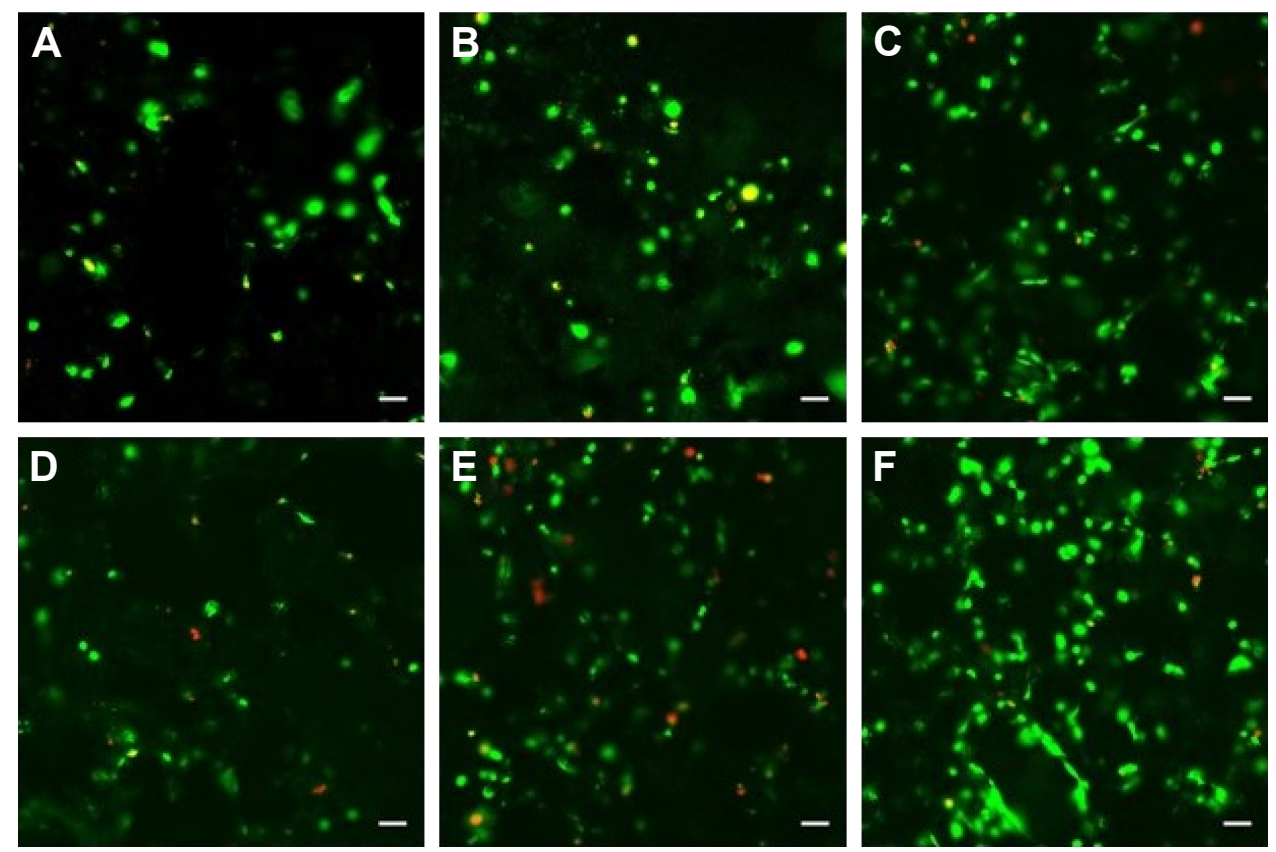

Figure 7 LSCM micrographs of MC3T3-EI cell (scale bars, $50 \mu \mathrm{m}$ for all panels) culture in (A) dichloromethane group for 3 days, (D) dichloromethane group for 7 days, (B) mixture group for 3 days, (E) mixture group for 7 days, (C) SF/PLLA 2:8 group for 3 days and (F) SF/PLLA 2:8 group for 7 days (live cells are stained green and dead cells are red).

Abbreviations: LSCM, laser scanning confocal microscope; SF, silk fibroin; PLLA, poly(L-lactic acid).

as a mixture and SF/PLLA 2:8 groups, were subjected to cell viability measurement based on live-dead assay of MC3T3-E1 cells after 3 and 7 days. The fluorescent staining analyses (Figure 7) demonstrated an increase in bright green dots representing the uniform and extensive distribution of live MC3T3-E1 cells on all the scaffolds. This result also replicates the observations of Figure 6 qualitatively and represents the highest number of live cells in scaffolds with SF/PLLA weight ratio 2:8.

\section{Osteogenic differentiation}

Growth and differentiation of osteoblasts are further confirmed by observing the progression of various markers responsible for it. MC3T3-E1 cell seeding density, as well as different concentrations of dexamethasone, would affect the results of osteogenic differentiation. ${ }^{42}$ In order to compare the differentiation potential, the MC3T3-E1 cells were induced at different concentrations of dexamethasone and cultured at varying cell seeding density to determine the osteogenic differentiation pathways. The degree of ECM mineralization was measured by staining with Alizarin Red and the respective bright field images of stained cells are shown in Figure S3. After 7 days, the staining intensity reached a maximum in a culture containing $10^{-8} \mathrm{M}$ dexamethasone and at initial seeding densities of 10,000 cells/well, which revealed that a high cell seeding density and low concentrations of dexamethasone can benefit osteogenic differentiation.

\section{ALP activity}

The ALP activity assay was performed on MC3T3-E1 cells in contact with scaffolds prepared using dichloromethane, mixture and SF/PLLA scaffolds with a weight ratio of 2:8 on days 7,14 and 21 after being cocultured in osteogenic medium. The ALP activity (Figure 8A) increased during the 14-day culture period and decreased later. The highest level of ALP activity was recorded on day 14 from cells cultured on the SF/PLLA scaffolds in comparison with other scaffolds significantly ( $\sim 134 \%$ more than the mixture group), however, ALP activity was also increased in the mixture group ( $116 \%$ more than the dichloromethane group). This is evident that the addition of SF showed an increased level of ALP activity.

\section{OC and COL-I content}

The osteogenic potential of MC3T3-E1 cells was assessed via the quantification of OC and COL-1 expression. The expression levels of both OC and COL-1 were found to be upregulated in all the groups after 14 days, and the latter decreased (Figure 8). Statistical analysis indicated that there was a significant difference in OC expression between all groups on day 14, and found that the expression levels of both OC and COL-1 are significantly higher in cells treated with SF/PLLA scaffolds (2:8; Figure 8B and C). However, the levels of COL-1 decreased significantly in the treatment group (ie, mixture and SF/PLLA [2:8] scaffolds after 14-day 

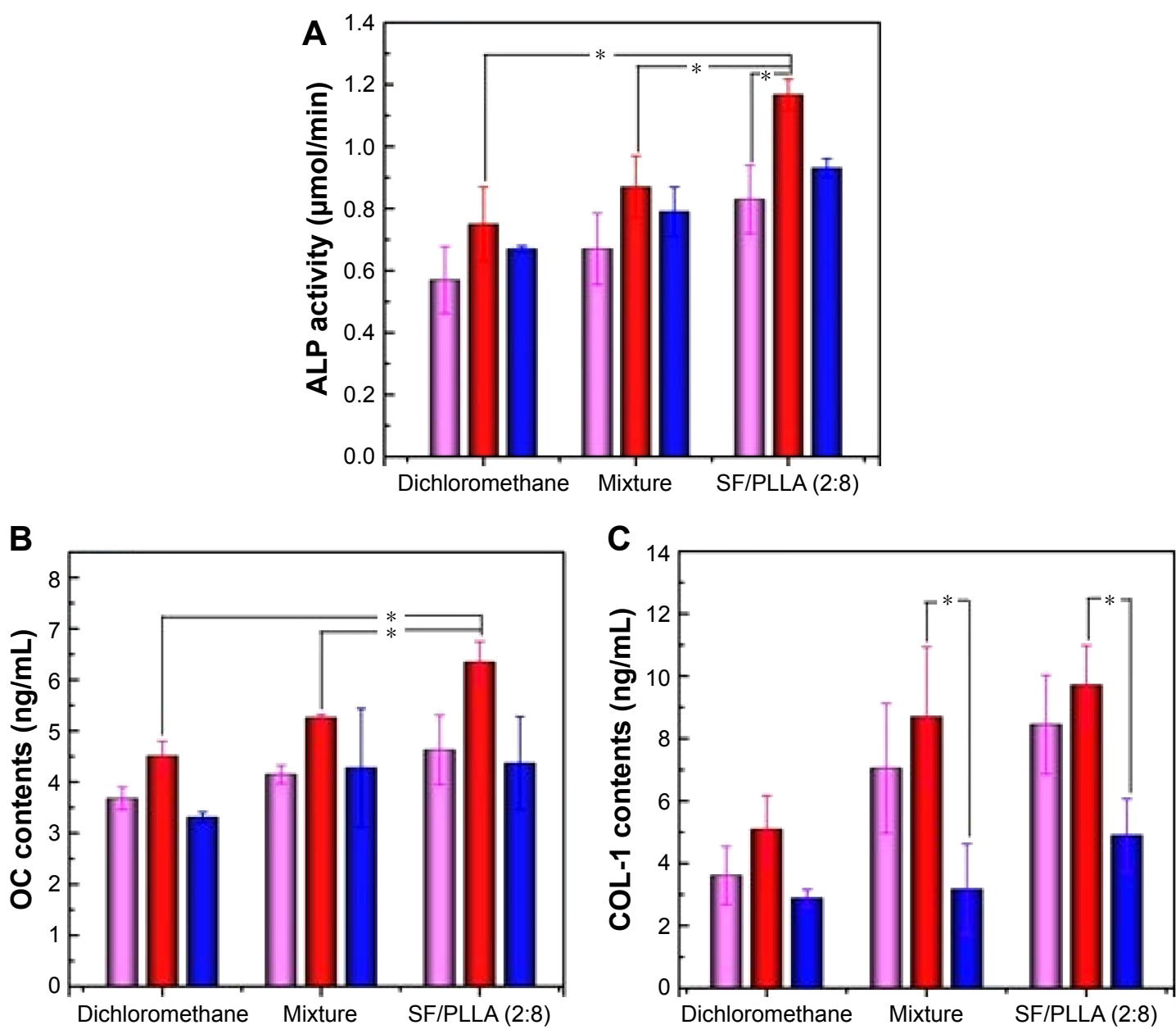

$\square 7 \mathrm{~d} \square 14 \mathrm{~d} \square 21 \mathrm{~d}$

Figure 8 (A) ALP activity, (B) OC and (C) COL-I content of MC3T3-EI cells on PLLA synthesized in dichloromethane as well as a solvent mixture (dichloromethane and dioxane), and SF/PLLA (2:8) scaffolds after 7,14 and 21 days $(* P<0.05)$.

Abbreviations: ALP, alkaline phosphatase; OC, osteocalcin; COL-I, collagen I; PLLA, poly(L-lactic acid); SF, silk fibroin; d, days.

culture period (Figure 8C). It was found that the addition of SF showed an increased level of OC and COL-1 expression; this process of the change in osteoblast-specific markers (ALP, OC and COL-1) during the stages of differentiation is useful in monitoring the osteoblastic phenotype of MC3T3-E1 cells. ${ }^{14,43,44}$

\section{Discussion}

Meticulous reflection of organ physiology is a key challenge during tissue engineering process. Although many approaches related to this process are being employed to generate various scaffolds, the applicability is still in infancy due to the lack of a convenient or feasible surface to manipulate cell behavior during tissue regeneration. Herewith, we designed the SF nanoparticle-embedded PLLA scaffolds with altered surface topographies, corresponding to increased surface ruggedness and hydrophilicity of polymer to manipulate the cell behavior during the regeneration of targeted tissue significantly.
The material design outline is discussed in brief. Initially, SF polymer is processed through SEDS for the precipitation of nanosize particles. These nanoparticles are dispersed into either of the solvents and packed along with porogen (AB) into PLLA and subjected to $\mathrm{SC}-\mathrm{CO}_{2}$ treatment in a highpressure vessel for phase inversion results in SF-embedded PLLA scaffolds. Furthermore, the porogen is decomposed via extraction for the generation of interconnected pores with altered size. The size of pores is controllable and possessed excellent mechanical properties.

The PLLA scaffolds with different morphologies were precipitated provided different solvent conditions such as 1,4-dioxane, dichloromethane and their combination (1:1 ratio). These solvents influenced significantly and resulted in altered surface properties evidenced by SEM observations (Figure 2), possessing dense network with micro as well as macrosize pores. The scaffolds in dichloromethane precipitated as microsize pore with thick wall surrounded, 
nanofibrous network with less pore size using dioxane and the combination of solvent resulted in a homogenous structure with fine particle texture and adjusted pore size due to optimized solvent properties, which is more suitable for cell growth and differentiation.

Indeed, incorporation of SF nanoparticles into the scaffolds improved the surface topography. The SF is precipitated into nanosize particles at an acceptable range in supercritical conditions provided and is quite feasible for dispersion in PLLA scaffolds. Out of all solvents used to pack, the mixture of solvents resulted in good dispersion of nanoparticles and the microstructure increased the surface roughness. Subsequently, the particles were intact with the polymer and located close to the pore wall, which can be helpful to enhance cell differentiation. Furthermore, we have altered the compositions of SF and PLLA during packing. Increase in SF amounts resulted in its improved dispersion ability but higher amounts of SF in the formulation may result in its separation during supercritical fluid operation. However, we have chosen the formulation SF:PLLA (2:8) as optimum scaffold packing as the SF nanoparticles are distributed uniformly with improved surface roughness, and further experiments related to cell differentiation are studied.

To evaluate the biocompatibility of the designed scaffolds, L929 normal cells were chosen to test the in vitro cytotoxicity test. This study demonstrated that cells are extremely viable in all the treatments, irrespective of SF amounts and solvents of packing. Later, the cell morphological observations revealed that they were grown normally in a fusiform way with no significant changes in morphology. This sign shows up that the designed scaffolds are biocompatible and tremendously feasible to take the charge of osteoblast differentiation.

Furthermore, cell adhesion studies were performed using MC3T3-E1 cells. The studies revealed that the adhesion rate of cells to scaffolds packed in the solvent mixture is higher than the control and other treatments, with scaffold-packed individual solvents showing the optimum. Similarly, SF incorporation also influenced the adhesion rate where SF:PLLA $(2: 8)$ has shown higher adhesion rate demonstrating that well-dispersed SF nanoparticles with optimum surface ruggedness improved the adhesion of cells immensely. In addition, the SF nanoparticles enhanced the adhesion rate by improving the hydrophobic nature of PLLA scaffolds. Subsequently, the scaffolds stimulate the adhered cells, and this ability was observed by recording the cell proliferation rate after harvesting the cells at different time points. As expected, the proliferation rate is significantly higher after 7 days of incubation with the SF:PLLA (2:8) scaffolds due to improved metabolic activities of the adhered cells. These scaffolds possessed higher surface area that promotes interaction of cell materials extensively. The increase in SF composition resulted in agglomerates, which hinder the interconnectivity between pores and limit space for cell communication with surroundings. At lower SF amounts, the cell proliferation is halted as the metabolic activity might be stabilized. LSCM results are in agreement and confirmed the abovementioned results.

Osteogenic differentiation is one of the key processes of bone regeneration. Cell seeding density, as well as different concentrations of dexamethasone, would affect the results of osteogenic differentiation. ${ }^{42}$ The differentiation potential was compared inducing different dexamethasone amounts through measuring various pathways of differentiation utilizing biochemical cues as markers. ALP is an early-stage marker of osteogenic differentiation, and its expression may affect the progression. $^{45,46}$ The differentiation of MC3T3-E1 cells into osteoblastic phenotype was quantitatively determined by ALP activity, so the commencement and complete differentiation were studied via ALP activity. In addition, active osteoblasts in bone matrices synthesize COL-1 protein abundantly, which acts as a conductive material to mineral deposition. It also binds to noncollagenous matrix proteins that initiate and regulate mineralization. ${ }^{43,47} \mathrm{OC}$ is produced by mature osteoblasts during mineralization and found in the fully developed mineralized matrix. ${ }^{48}$ Meanwhile, the increased levels of OC and COL-1 indicated the concluding phase of ECM mineralization. ${ }^{28,46} \mathrm{SF}$ nanoparticles packing in PLLA scaffolds increased the expression of all osteogenic differentiation markers, ALP, OC and COL-1, significantly until 14 days of culture, but a decrease was initiated in the levels of all markers keeping a low expression of differentiation. Hence, these observations eventually demonstrated that SF nanoparticles influenced PLLA scaffolds immensely to make them suitable for osteogenic growth and tissue differentiation.

\section{Conclusion}

This study investigated the potential of PLLA scaffolddecorated SF nanoparticles with different topological structures for bone tissue regeneration. The engineered scaffolds with controlled physical topography and proper biochemical cues could enable the interaction between MC3T3-E1 cells and scaffolds. The interconnected porous architecture of PLLA scaffolds was beneficial in promoting cell adhesion, viability and proliferation. Compared with 
PLLA scaffolds, the SF/PLLA composite scaffolds with a weight ratio of 2:8 exhibited a better capability of inducing a higher level of osteoblast-specific markers and result in greater amount of bone matrix. This study demonstrates the potential advancement toward tissue engineering scaffolds with controlled physical topography and proper biochemical cues for repairing the damaged tissue.

\section{Acknowledgments}

Financial supports from National Natural Science Foundation of China (31570974, U1605225 and 31470927), Public Science and Technology Research Funds Projects of Ocean (201505029) and Promotion Program for Young and Middleaged Teacher in Science and Technology Research of Huaqiao University (ZQN-PY107) are gratefully acknowledged.

\section{Disclosure}

The authors report no conflicts of interest in this work.

\section{References}

1. Lui PPY, Rui YF, Ni M, Chan KM. Tenogenic differentiation of stem cells for tendon repair - what is the current evidence? J Tissue Eng Regen Med. 2011;5(8):e144-e163.

2. Ricchetti ET, Aurora A, Iannotti JP, Derwin KA. Scaffold devices for rotator cuff repair. J Shoulder Elbow Surg. 2012;21(2):251-265.

3. Langer R, Vacanti JP. Tissue engineering. Science. 1993;260(5110): 920-926.

4. Hollister SJ. Scaffold design and manufacturing: from concept to clinic. Adv Mater Deerfield. 2009;21(32-33):3330-3342.

5. Shastri VP. In vivo engineering of tissues: biological considerations, challenges, strategies, and future directions. Adv Mater Deerfield. 2009; 21(32-33):3246-3254.

6. Viswanathan P, Ondeck MG, Chirasatitsin S, et al. 3D surface topology guides stem cell adhesion and differentiation. Biomaterials. 2015;52: 140-147.

7. Shahini A, Yazdimamaghani M, Walker KJ, et al. 3D conductive nanocomposite scaffold for bone tissue engineering. Int J Nanomedicine. 2014;9:167-181

8. Liu C, Xia Z, Czernuszka JT. Design and development of threedimensional scaffolds for tissue engineering. Chem Eng Res Des. 2007; 85(7):1051-1064.

9. Stevens MM. Biomaterials for bone tissue engineering. Mater Today. 2008;11(5):18-25.

10. Curtis A, Wilkinson C. Nanotechniques and approaches in biotechnology. Trends Biotechnol. 2001;19(3):97-101.

11. McKenzie JL, Waid MC, Shi R, Webster TJ. Decreased functions of astrocytes on carbon nanofiber materials. Biomaterials. 2004;25(7-8): 1309-1317.

12. Higuchi A, Kumar SS, Ling Q-D, et al. Polymeric design of cell culture materials that guide the differentiation of human pluripotent stem cells. Prog Polym Sci. 2017;65:83-126.

13. Liu X, Ma PX. Phase separation, pore structure, and properties of nanofibrous gelatin scaffolds. Biomaterials. 2009;30(25):4094-4103.

14. Nune KC, Misra RDK, Gaytan SM, Murr LE. Interplay between cellular activity and three-dimensional scaffold-cell constructs with different foam structure processed by electron beam melting. $J$ Biomed Mater Res A. 2015;103(5):1677-1692.

15. Shao Y, Fu J. Integrated micro/nanoengineered functional biomaterials for cell mechanics and mechanobiology: a materials perspective. $A d v$ Mater. 2014;26(10):1494-1533.
16. Mata A, Kim EJ, Boehm CA, Fleischman AJ, Muschler GF, Roy S. A three-dimensional scaffold with precise micro-architecture and surface micro-textures. Biomaterials. 2009;30(27):4610-4617.

17. Pina S, Oliveira JM, Reis RL. Natural-based nanocomposites for bone tissue engineering and regenerative medicine: a review. Adv Mater Deerfield. 2015;27(7):1143-1169.

18. Higuchi A, Ling Q-D, Kumar SS, et al. Physical cues of cell culture materials lead the direction of differentiation lineages of pluripotent stem cells. J Mater Chem B. 2015;3(41):8032-8058.

19. Higuchi A, Ling QD, Chang Y, Hsu ST, Umezawa A. Physical cues of biomaterials guide stem cell differentiation fate. Chem Rev. 2013;113(5): 3297-3328.

20. Flemming RG, Murphy CJ, Abrams GA, Goodman SL, Nealey PF. Effects of synthetic micro- and nano-structured surfaces on cell behavior. Biomaterials. 1999;20(6):573-588.

21. Curtis A, Wilkinson C. Topographical control of cells. Biomaterials. 1997;18(24):1573-1583.

22. Dvir T, Timko BP, Kohane DS, Langer R. Nanotechnological strategies for engineering complex tissues. Nat Nanotechnol. 2011;6(1): 13-22.

23. Beachley V, Wen X. Polymer nanofibrous structures: fabrication, biofunctionalization, and cell interactions. Prog Polym Sci. 2010; 35(7):868-892.

24. Liu Q, Wang W, Zhang L, et al. Involvement of $\mathrm{N}$-cadherin/ $/$ catenin interaction in the micro/nanotopography induced indirect mechanotransduction. Biomaterials. 2014;35(24):6206-6218.

25. Persson M, Lorite GS, Kokkonen HE, et al. Effect of bioactive extruded PLA/HA composite films on focal adhesion formation of preosteoblastic cells. Colloids Surf B Biointerfaces. 2014;121:409-416.

26. Gittens RA, McLachlan T, Olivares-Navarrete R, et al. The effects of combined micron-/submicron-scale surface roughness and nanoscale features on cell proliferation and differentiation. Biomaterials. 2011; 32(13):3395-3403.

27. Khang D, Choi J, Im Y-M, et al. Role of subnano-, nano- and submicronsurface features on osteoblast differentiation of bone marrow mesenchymal stem cells. Biomaterials. 2012;33(26):5997-6007.

28. Song S, Kim EJ, Bahney CS, Miclau T, Marcucio R, Roy S. The synergistic effect of micro-topography and biochemical culture environment to promote angiogenesis and osteogenic differentiation of human mesenchymal stem cells. Acta Biomater. 2015;18:100-111.

29. Yamano S, Haku K, Yamanaka T, et al. The effect of a bioactive collagen membrane releasing PDGF or GDF-5 on bone regeneration. Biomaterials. 2014;35(8):2446-2453.

30. Martínez E, Engel E, Planell JA, Samitier J. Effects of artificial microand nano-structured surfaces on cell behaviour. Ann Anat. 2009;191(1): 126-135.

31. Bettinger CJ, Langer R, Borenstein JT. Engineering substrate topography at the micro- and nanoscale to control cell function. Angew Chem Int Ed. 2009;48(30):5406-5415.

32. Chen A-Z, Zhao C, Wang S-B, Liu Y-G, Lin D-L. Generation of porous poly-l-lactide microspheres by emulsion-combined precipitation with a compressed CO2 antisolvent process. J Mater Chem B. 2013; 1(23):2967-2975.

33. Deng A, Chen A, Wang S, et al. Porous nanostructured poly-1-lactide scaffolds prepared by phase inversion using supercritical $\mathrm{CO} 2$ as a nonsolvent in the presence of ammonium bicarbonate particles. J Supercrit Fluids. 2013;77:110-116.

34. Yang D-Z, Chen A-Z, Wang S-B, Li Y, Tang X-L, Wu Y-J. Preparation of poly(L-lactic acid) nanofiber scaffolds with a rough surface by phase inversion using supercritical carbon dioxide. Biomed Mater. 2015; 10(3):035015.

35. Nair LS, Laurencin CT. Biodegradable polymers as biomaterials. Prog Polym Sci. 2007;32(8-9):762-798.

36. Callahan LA, Xie S, Barker IA, et al. Directed differentiation and neurite extension of mouse embryonic stem cell on aligned poly(lactide) nanofibers functionalized with YIGSR peptide. Biomaterials. 2013; 34(36):9089-9095. 
37. Reverchon E, Pisanti P, Cardea S. Nanostructured PLLA-hydroxyapatite scaffolds produced by a supercritical assisted technique. Ind Eng Chem Res. 2009;48(11):5310-5316.

38. Chen AZ, Chen LQ, Wang SB, Wang YQ, Zha JZ. Study of magnetic silk fibroin nanoparticles for massage-like transdermal drug delivery. Int J Nanomedicine. 2015;10:4639-4651.

39. Kundu B, Rajkhowa R, Kundu SC, Wang X. Silk fibroin biomaterials for tissue regenerations. Adv Drug Deliv Rev. 2013;65(4):457-470.

40. Zhao Z, Li Y, Chen A-Z, et al. Generation of silk fibroin nanoparticles via solution-enhanced dispersion by supercritical CO2. Ind Eng Chem Res. 2013;52(10):3752-3761.

41. López-Pérez PM, da Silva RMP, Sousa RA, Pashkuleva I, Reis RL. Plasma-induced polymerization as a tool for surface functionalization of polymer scaffolds for bone tissue engineering: an in vitro study. Acta Biomater. 2010;6(9):3704-3712.

42. Talukdar S, Nguyen QT, Chen AC, Sah RL, Kundu SC. Effect of initial cell seeding density on 3D-engineered silk fibroin scaffolds for articular cartilage tissue engineering. Biomaterials. 2011;32(34):8927-8937.

43. Ohsawa K, Neo M, Matsuoka H, et al. The expression of bone matrix protein mRNAs around beta-TCP particles implanted into bone. J Biomed Mater Res. 2000;52(3):460-466.
44. Lian JB, Stein GS. Concepts of osteoblast growth and differentiation: basis for modulation of bone cell development and tissue formation. Crit Rev Oral Biol Med. 1992;3(3):269-305.

45. Wang H, Li Y, Zuo Y, Li J, Ma S, Cheng L. Biocompatibility and osteogenesis of biomimetic nano-hydroxyapatite/polyamide composite scaffolds for bone tissue engineering. Biomaterials. 2007;28(22): 3338-3348.

46. Kim IG, Hwang MP, Du P, et al. Bioactive cell-derived matrices combined with polymer mesh scaffold for osteogenesis and bone healing. Biomaterials. 2015;50:75-86.

47. Ehara A, Ogata K, Imazato S, Ebisu S, Nakano T, Umakoshi Y. Effects of $\alpha$-TCP and TetCP on MC3T3-E1 proliferation, differentiation and mineralization. Biomaterials. 2003;24(5):831-836.

48. Ripamonti U, Klar RM, Parak R, Dickens C, Dix-Peek T, Duarte R. Tissue segregation restores the induction of bone formation by the mammalian transforming growth factor-beta(3) in calvarial defects of the non-human primate Papio ursinus. Biomaterials. 2016;86:21-32. 


\section{Supplementary materials}

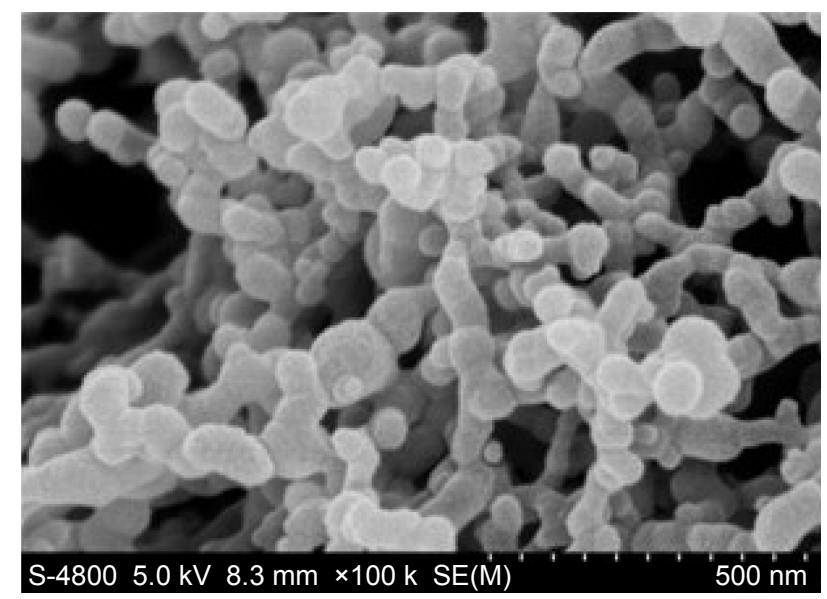

Figure SI SEM image of SF nanoparticles prepared by the SEDS process.

Abbreviations: SEM, scanning electron microscope; SF, silk fibroin; SEDS, solution-enhanced dispersion using supercritical carbon dioxide.
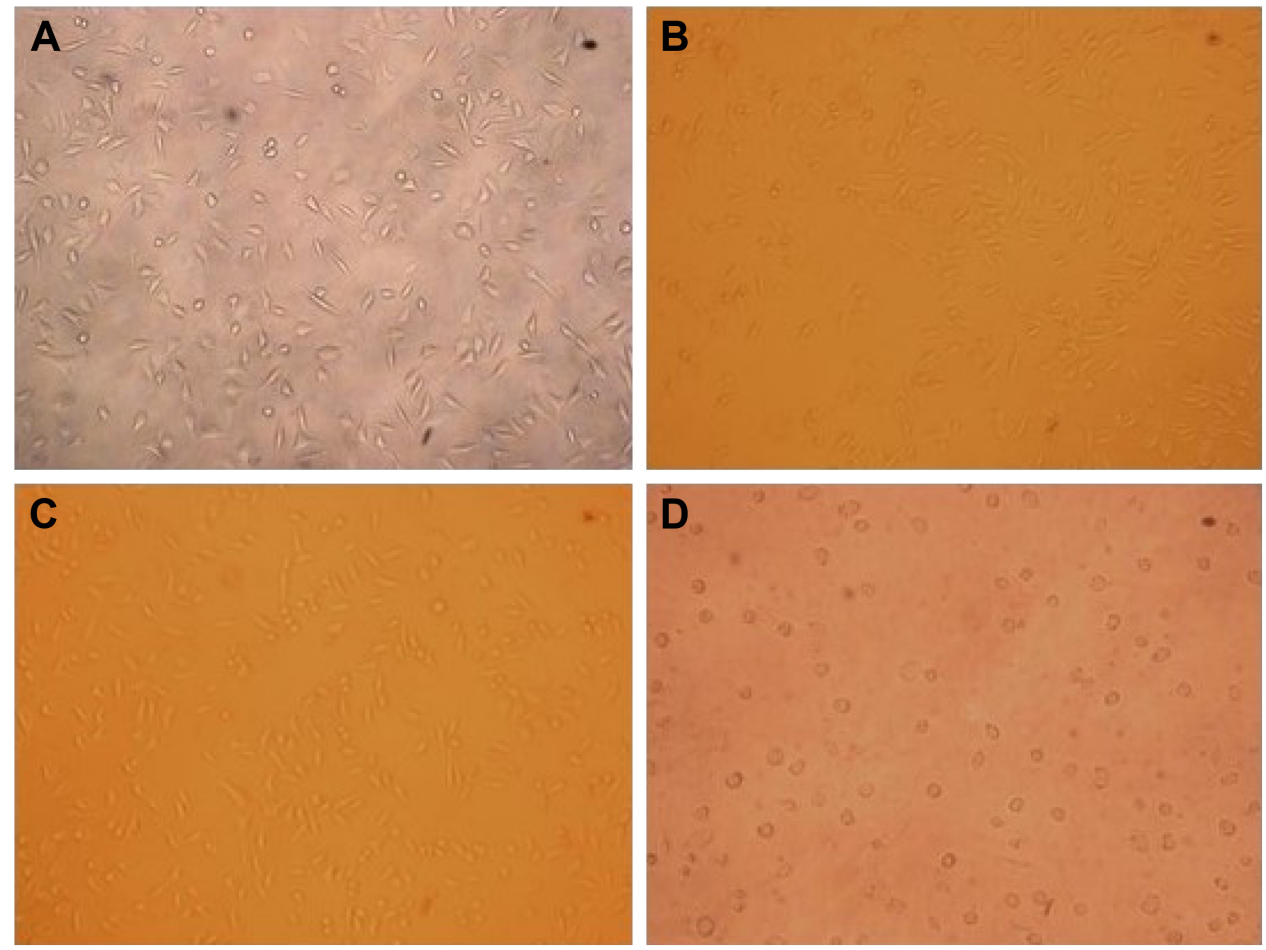

Figure S2 Optical micrographs of L929 cells cultured for $48 \mathrm{~h}(\times 100)$, (A) negative control, (B) $1.0 \mathrm{mg} / \mathrm{mL}$, (C) $2.0 \mathrm{mg} / \mathrm{mL}$ of the leach liquors of SF/PLLA composite scaffolds and (D) positive control.

Abbreviations: SF, silk fibroin; PLLA, poly(L-lactic acid). 
$10^{-6} M$
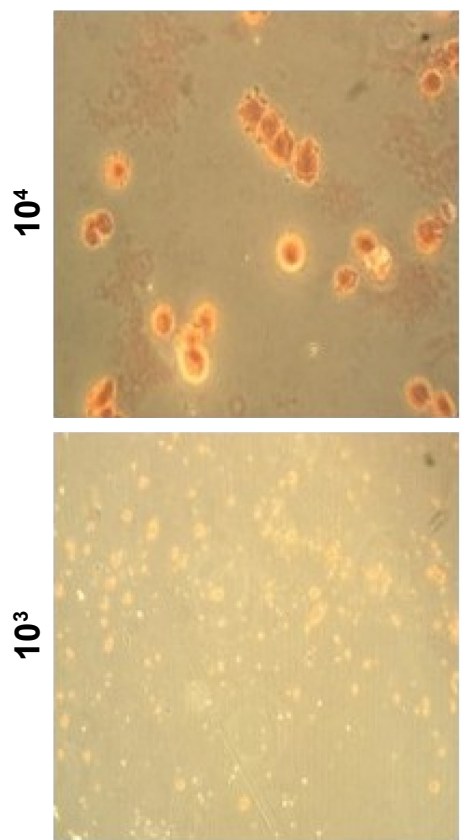

$10^{-7} \mathrm{M}$
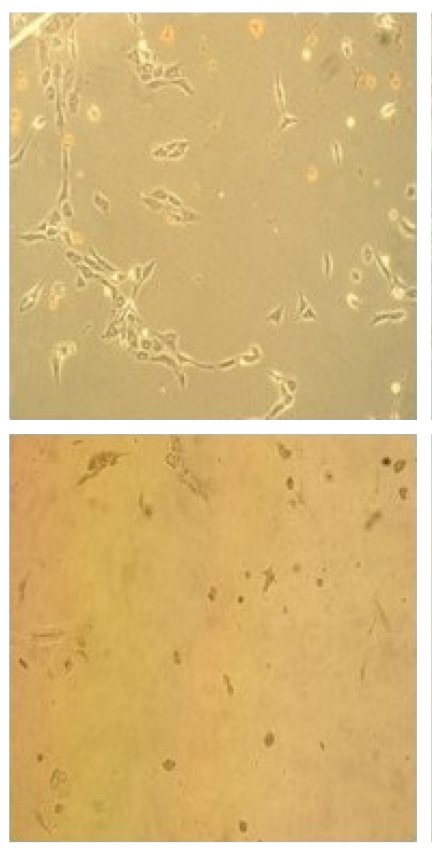

$10^{-8} \mathrm{M}$
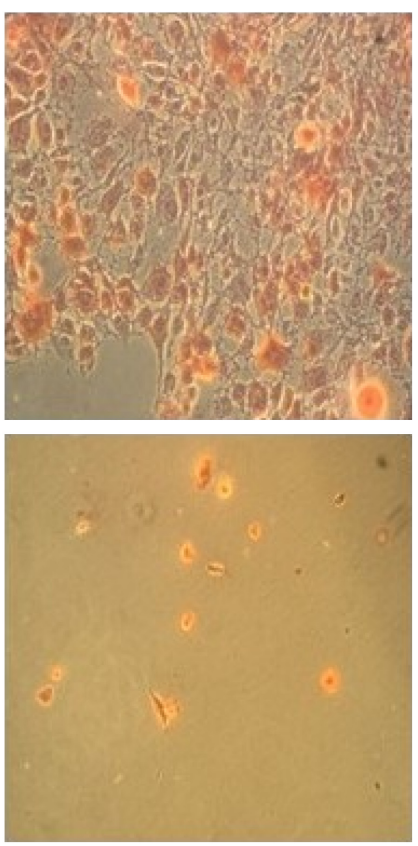

Figure S3 Optical images of MC3T3-EI mineralization section in different osteoinductive conditions for 7 days $(\times 100)$.

Notes: $10^{3}, 10^{4}$ : cell seeding density; $10^{-6}, 10^{-7}, 10^{-8}$ : dexamethasone concentration.

\section{Publish your work in this journal}

The International Journal of Nanomedicine is an international, peerreviewed journal focusing on the application of nanotechnology in diagnostics, therapeutics, and drug delivery systems throughout the biomedical field. This journal is indexed on PubMed Central, MedLine, CAS, SciSearch ${ }^{\circledR}$, Current Contents ${ }^{\circledR} /$ Clinical Medicine,
Journal Citation Reports/Science Edition, EMBase, Scopus and the Elsevier Bibliographic databases. The manuscript management system is completely online and includes a very quick and fair peer-review system, which is all easy to use. Visit http://www.dovepress.com/ testimonials.php to read real quotes from published authors. 